\title{
The Causes, Manifestations, Negative Influences of the Moral Nihilism in Current China and Solutions to It
}

\author{
Gao Peng \\ School of Humanities \\ Tongji University \\ Shanghai, China 200092
}

\begin{abstract}
The Moral Nihilism is a practical problem in the process of modernization in China, the main connotation of which is the negation and nihilization to all moral norms and moral values.(Yang Jinhua 10) This problem has many negative influences on the stability, harmony, development and progress of our society. Therefore, the study about this issue is particularly necessary and important. However, only a limited amount of research achievements have been made and published on this issue by domestic scholars, and these achievements on this issue are not comprehensive and deep enough. In view of this, the author decides to give a relatively deeper and more comprehensive analysis on this issue. In this paper, the author consciously follows the principle of the unity of logic and history, the unification of theory and reality. And then, he mainly adopts the methods of literature research, systematic analysis, induction, deduction. With the principles and methods above, the author give his analysis as follows. First of all, based on the history and reality of China, the causes of Moral Nihilism are analyzed. Then, according to the current social reality, the author analyzes the manifestation and the negative influences of Moral Nihilism. Finally, the author puts forward some solutions to Moral Nihilism based on the recent social reality. Therefore, this paper provides a relatively helpful theoretical reference for comprehensively analyzing and solving the Moral Nihilism in current China.
\end{abstract}

Keywords-the Moral Nihilism; causes; manifestations; negative influences; solutions

\section{INTRODUCTION}

The Moral Nihilism is a practical problem in the process of modernization in China, the main connotation of which is the negation and nihilization to all moral norms and moral values.(Yang Jinhua 10) . This problem has many negative influences on the stability and development of our society. Therefore, the study about this issue is particularly necessary. However, only a limited amount of research achievements have been made on this issue by domestic scholars, and these achievements on this issue are not comprehensive and deep enough. Concerning this, the author decides to give a relatively deeper and more comprehensive analysis on this issue.
In this paper, the author consciously follows the principle of the unity of logic and history, the unification of theory and reality. And then, he mainly adopts the methods of literature research, systematic analysis, induction, deduction. With the principles and methods above, the author give his analysis as follows. First of all, based on the history and reality of China, the causes of Moral Nihilism are analyzed. Then, according to the current social reality, the author analyzes the manifestation and the negative influences of Moral Nihilism. Finally, the author puts forward some solutions to Moral Nihilism based on the recent social reality. Therefore, this paper provides a relatively helpful theoretical reference for comprehensively analyzing and solving the Moral Nihilism in current China.

\section{THE CAUSES OF THE MORAL NIHILISM IN CURRENT CHINA}

The Moral Nihilism is a practical problem in the process of modernization in China, the main connotation of which is the negation and nihilization to all moral norms and moral values.(Yang Jinhua 10) This problem has many negative influences on the stability, harmony, development and progress of our society. Therefore, it is necessary for us to deeply analyse and effectively solve the problem. In order to effectively solve this problem, we must deeply analyze the causes of the problem, which will help us to put forward effective solutions. The Moral Nihilism in current China has its profound and complicated reasons as follows.

A. The Vacillation of the Traditional Moral Norm System Brought About by the Liberation Movements Since the New Cultural Movement

The Moral Nihilism in current China is not only related to the actual social situations, but also related to some important historical events. In the author's view, in the new cultural movement more than a hundred years ago, some modern intellectuals vigorously advocated "democracy" and "science" and drastically criticized the traditional culture, which shook the traditional moral norm and value systems. Then, in the Cultural Revolution, "breaking the four old kind of things" further cleared people's minds of the traditional moral consciousness and moral concepts. Fortunately, since 
Chairman Mao Zedong's personal worship was universally deep nationwide, socialist moralities advocated by Comrade Mao Zedong still had relatively strong binding on people's behaviors. Therefore, the ideological state and moral situation of the whole society was very positive at that time. However, after Chairman Mao Zedong's death, his personal worship and belief in socialist morality gradually faded. After that, China started the process of reform and opening up.Thus, a plenty of capital, technologies and advanced management experience were absorbed to boost the economic development. However, at the same time, the western social ethos also had a large-scale influx into China, some negative parts of which misled and corroded people's thoughts to some extent. Consequently, the living space of traditional moral concepts and norms were further compressed. As a result, the traditional moral beliefs in the people's minds gradually declined and eventually nearly completely disappeared. Therefore, this has led to the formation of Moral Nihilism in current China to some extent.

\section{B. The Influences of Negative Western Social Ethos}

In the process of the reform and opening up, China introduced western advanced production technologies and management experience, which promoted the rapid development of domestic economy to some extent. At the same time, the western social ethos poured into China, and they were uneven. Among them, there were individualism, liberalism, money worship, hedonism and so on, which had severely negative influences on China. These social ethos corroded Chinese's original moral consciousness and concepts, while aroused the consciousness and the concepts of selfishness among Chinese. Thus, the problem of Moral Nihilism has emerged in a small number of people to some extent.

\section{The Factors of Evil in Human Nature Stimulated by the Development of Market Economy and the Logic of Capital}

After starting the reform and opening up, China gradually liberalized the policy of restricting the development of market economy. The Party's 14th National Congress formally put forward the socialist market economy system as the goal of economic system reform. Since then, China has embarked on a pattern of the developing a market economy under the premise of a socialist basic system. On the one hand, this pattern has stimulated the vitality of all kinds of market entities and brought rapid development of the domestic economy. However, at the same time, the spontaneity of market regulation resource allocation also caused that in order to pursue their own economic interests, a small number of market subjects broke through the bottom line of morality and even the law, and made some behaviors violating morality and even the law. Therefore, these behaviors eventually spawned and encouraged a culture of self-interest, regardless of others.

On the other hand, the Moral Nihilism is also the result of the evil factors in human nature inspired by the logic of capital since the reform and opening up. The essence of capital is the pursuit of appreciation. Driven by this nature, it dares to break through the bottom line of morality and law, and act against morality and even law. After the starting of reform and opening up, China has also seen new formats such as the non-public sector of the economy. To some extent, its producers and operators has also been spokesmen of capital, and has been dominated by the logic of capital. As a result, they have also regarded pursue value-added or the pursuit of profit as their primary goal of production and management activities. Driven by the nature of capital, some of them have broken through the bottom line of morality and even law, and have used some improper means to reap more economic benefits. This is also a reason for the emergence of Moral Nihilism in a small number of social members.

\section{The Law Systems of the Society Are Not Perfect}

Since the reform and opening up, China's modernization process has entered a period of accelerated development, and the society has undergone dramatic transformation, which has brought about many new formats and subjects in the field of social production and life. However, the construction of the law systems has always been lagged behind, leading to the imperfect law systems in some production. As a result, some people have hit the edge of the law, have exploited the loopholes of the law, and have done some acts that are against morality but cannot be qualified as violations of the law under the current legal systems, thus obtaining more economic benefits. This is also one of the causes of Moral Nihilism.

\section{E. The New Social Moral System Is Still in the Process of Being Formed and perfected, and the Moral Binding Force of Which on the Members of the Society Needs to Be Improved}

Since the reform and opening up, with the rapid transformation of Chinese society from traditional to modern, as well as the dramatic changes in social production and life, the traditional moral systems has disappeared. However, the moral system, which adapts to the new social situation and reality, is still in the process of being formed, and the people's approves rate of it needs to be improved, and its binding force on people's social behavior is still weak. As a result, this also contributes to the formation of Moral Nihilism to a certain extent.

\section{F. The Social Incentive and Guarantee Mechanism for Morally Good Behaviors Is Not Perfect}

The existence of Moral Nihilism has a certain relationship with the unsound incentive mechanism of morally good behaviors. For example, why people are more indifferent to those who need help nowadays? The reasons can be summarized as following two points: on the one hand, it is because of the selfishness of people to some degree; on the other hand, people's nature of self-preservation is also related. Specifically, people fear making morally good behaviors to help others not only without rewards, but will be blackmailed by the recipients, which not only causes economic losses, but also causes mental distress and troubles and entanglements in life. Contrarily, if the social incentive and guarantee mechanism for morally good behaviors were 
perfect, there would be more people making morally good behaviors to help others and contribute to the society.

\section{THE MANifESTATIONS OF THE MORAL NIHILISM IN CURRENT CHINA}

The Moral Nihilism is mainly manifested in defiance of moral values and moral models, lack of moral responsibility, and wanton actions against the bottom line of morality. (Yang Jinhua 10)

\section{A. Contempt for Moral Values and Moral Models}

One of the manifestations of the Moral Nihilism is contempt for moral values and moral models. In the opinions of people who believe in the Moral Nihilism, moral values are either completely illusory or not worth mentioning, and there is little value or meaning in moral models. This viewpoint and its expressions in real social life can also find some corresponding examples. For example, the thoughts and sayings of querying Lei Feng, satirizing Lai Ning, and regarding Guo Mingyi as a "fool" occurred in the past few years. To some extent, these objective and abnormal social phenomena reflect the contempt of some social groups for moral values and moral models.

\section{B. Lacking Sense of Moral Responsibility}

Another manifestation of the Moral Nihilism is a lack of moral responsibility, or, in other words, a moral apathy or numbness.

In this respect, some of the distorted, cold social phenomena in real social life will always make us heartache and unrelieved. For example, "Xiao Yue Yue Accident" happened a few years ago in Guangdong Province has once stung the whole country. In this accident, when a young girl was hit down by a car, no one went to help, and consequently she was crushed a few times by other cars. In the whole process of the accident, although there was some people passing by, but no one went up to help her. At last, a old woman called Chen Xianmei saw her and rescued her. When the author saw the news, he was moved by Chen's good deeds on the one hand. On the other hand, the author also has to question passers-by before the Chen Xianmei why not to help her when seeing the girl. The reason is that they lacked the sense of moral responsibility and had a moral apathy or moral numbness. In addition, we often see the sad news in the mass media like "after an elderly person fall down on the street, no one come up to help him or her" and so on. After seeing an old person fell down, some of the passers-by pretended not to see and help him or her, this also reflected their moral numbness and moral indifference. In a word, the above social phenomena reflect the social reality that the lack of moral responsibility, moral apathy or moral numbness has been objectively existed in a certain scope, which has become a social problem that cannot be ignored.

\section{Wantonly Making Behaviors Contrary to the Moral Bottom Line}

In recent China, the behaviors violating moralities have existed in certain scope in many aspects of social life.
According to the realities of recent years, these behaviors violating morality are mainly reflected in the following aspects.

1) The manifestations in the economic field: In the economic field, the behaviors violating the moral bottom line is mainly manifested as breaking through the moral bottom line and violating the public moral norms for reaping the economic benefits. For example, a few years ago,the exposure of the "Sanlu" milk powder incident in China's milk powder industry, as well as some restaurants using gutter oil in the cooking process, and so on. These behaviors have obviously broken through the basic moral bottom line and the basic public moral norms and they have made great harm to the people's life and health. Consequently, they also have severely negative influences on the social stability and harmony. What's more, they also have extremely negative influences on the sustainable and healthy development of the socialist market economy.

2) The manifestations in the political field: In the political field, these behaviors violating the moral bottom line are mainly embodied as exchanging power for money and corruption. Corruption is not only an offence or crime, but also a bad behavior violating the political morality.

3) The manifestations in the cultural field: In the cultural field, the behaviors violating the moral bottom line are mainly reflected in the literary works or ideological viewpoints that violate the moral bottom line. For instance, the sealed magazine "Yan Huang Chun Qiu", which denigrated the revolutionary hero Qiu Shaoyun. What's more, there are still some vulgar literature and art works in recent society. And their producers do not hesitate to violate the moral bottom line in the field of culture in order to obtain economic benefits; In addition, in order to gain economic benefits or a prominent reputation, regardless of breaking the moral bottom line, shoddy, plagiarism.

4) The manifestations in the field of social affairs

a) The manifestations in the educational field: In the field of education, the behavior of violating the moral bottom line is mainly manifested as the behaviors violating the moralities of teachers and academic research.

- The behaviors violating the teachers' moralities. For example, "The Incident of Fled Teacher Fan" in the 2008 WenChuan earthquake. In this incident, as a teacher, Mr Fan did not give any active guidance or take any effective measures to help the whole class to escape from the classroom, but fled away alone first at the moment of the earthquake. Later, he also accepted the public media interview and said that he should flee first. In addition, sometimes there are some incidents that violate the teacher's morality and hurt the physical and mental health of the students.

- The behaviors violating academic moralities. The behaviors violating academic moralities is mainly manifested as that in the process of academic research, some college teachers or students plagiarize or steal 
academic achievements of others without obeying the academic moralities.

b) The manifestations in the medical field: In the medical field, the behaviors violating the moral bottom line are mainly the behaviors violating the medical ethics. For example, some doctors illegally charge patients "red envelopes" or extra rewards, and give patients medical items or drugs beyond the actual treatment needs. Also, doctors do business cooperation with medical representatives and collect their rebates, then irregularly recommend unnecessary drugs to the patients.

c) The manifestations in the pension field: In the field of pension, the behaviors violating the moral bottom line is mainly manifested by the abandoning and abusing the elderly. The behavior of abandoning the elderly is mainly embodied as children's abandoning their elderly parents. The behavior of abusing the elderly are embodied not only on some children who are not filial to their parents, and also in the pension institutions lacking professional moralities.

5) The manifestations in the ecological field: In the ecological field, or in the environmental protection field, the behaviors violating the moral bottom line in the ecological field are mainly embodied as reaping the economic benefits at the expense of the destruction of the ecological environment. In current society, although the government has made great efforts to promote the construction of ecological civilization. For example, it has issued a series of systems and policies in the field of environmental protection, strengthened the daily supervision of environmental protection, and increased the punishment for illegal acts of environmental protection. However, a few enterprises still have been reaping economic benefits at the expense of the environment. They have secretly been discharging untreated pollutants, causing serious pollution to the environment. Their behaviors above not only have violated environmental laws, but also have broken the bottom line of social morality. These behaviors also reflect the lack of basic social responsibility of the producers and operators of these enterprises. In addition, the behaviors violating the moral bottom line in the ecological field are also embodied as the illegal poaching of rare plants and wild animal. These two illegal behaviors are not only violating the law of environmental protection, but first breaking through the public moral bottom line of society. Their serious negative influence it that it will destroy the balance of natural ecosystem and finally threaten the sustainable existence and development of mankind itself.

\section{THE NEGAtive INFLUENCES OF THE MORAL NiHILISM IN CURRENT CHINA}

The Moral nihilism has a negative impact on the development of economy and society, which is manifested in the following points.

\section{A. The Negative Influences on Individuals}

Confucius said, "there is no man can live in the society without honesty." In other words, if a person does not have honesty, he or she cannot survive or develop in the society. Honesty is the most important and basic moral quality of a person. It is inferred that morality is the foundation of a person's foothold in the society. If a person is completely dominated by the Moral Nihilism and does not obey any moral values or norms at all, it is difficult for him or her to survive and develop in the society.

\section{B. The Negative Influences on the Country}

It was said in the chapter Ruling people of ancient classic Guanzi, "For a country, there are four dimensions: the sense and norms of propriety, the sense and norms of righteousness, the sense and norms of honesty, the sense and norms of shame. If the four dimensions malfunction, the country will ruin". From this, we can be seen that morality is an important foundation for the existence and development of a country. If the Moral Nihilism overflows in the whole society, it will affect the development and progress of the country and the stability and harmony of the society. Specifically, the negative influences of Moral Nihilism on our country are embodied in the following aspects.

1) The negative influences on economic construction: The negative influences of the Moral Nihilism in current China on economic construction is that it will lead to the negative effect of "The Bad money drives out the good ones" in the operation of market economy. Specifically, in the processes of production and operation, the immoral enterprises will take immoral even illegal means to make more profits, so they can make more, faster accumulation of capital as well as faster capital circulation. Therefore, they can continually expand reproduction and their economic scales. Contrarily, those real moral enterprises can not make the profits as high as the immoral, so their amount and the speed of capital accumulation and circulation are not as good as the immoral, thus they can not quickly expand reproduction. Consequently, their economic scales may atrophy gradually, which will make them eventually be out of the market.

2) The negative influences on political construction: The negative influences of the Moral Nihilism in current China on political construction is that it will lead to "the Tacitus trap". Specifically, the proliferation of moral nihilism in the political field will make government functionaries seek their own interests without obeying the moral norms, thus they may fall into the quagmire of corruption and harm the interests of the country and the people. As the time passes, the government will gradually lose the trust of the people. In other words, the credibility of the government among the people will eventually be lost. As a result, the government will be caught in the "Tacitus trap", which will lead to the consequence that there would be no people will believe in any policy promulgated by the government. Consequently, the whole Chinese political 
bureau and even the social stability of the country will be in danger.

3) The negative influences on cultural construction: The negative influences of the Moral Nihilism in current China on cultural construction is that it will influence the sustainable and healthy development of the whole social culture. Specifically, it will misleads the direction of cultural development, stifles the vitality of culture, and ultimately leads to the collapse of culture. The development of culture is also inseparable from the guidance of a certain system of moral values and norms. If the Moral Nihilism also invades the process of cultural development, it will mislead the direction of cultural development. As a result, in the developing process of the whole social culture, there may be some literary works or ideas violating the bottom line of morality, or make the culture become vulgar. Consequently, the culture will lose its own vitality and goes to self-depravity, which makes it difficult for the culture to achieve sustainable and healthy development.

4) The negative influences on social construction: The negative influences of the Moral Nihilism in current China to social construction lies in its influence on social stability, harmony and sustainable and healthy development. If the Moral Nihilism is rampant in the whole society, it will affect the process and effect of social construction, especially the development of some undertakings related to people's daily lives, such as education, medical treatment, pension and so on. Once these fields are eroded by the Moral Nihilism, many behaviors violating the bottom line of social public moralities will emerge, which will seriously affect the daily lives of the people, the stability and harmony as well as the sustained and healthy development of the whole society.

5) The negative influences on ecological construction: The negative influences of the Moral Nihilism in current China to ecological construction is that it exacerbates environmental problems. Recently, China has vigorously been strengthening the construction of ecological civilization. Therefore, the environmental problems are gradually being solved and environmental quality is gradually improved. However, if the Moral Nihilism floods the whole society, more enterprises will break through the bottom line of social public morality to reap more economic interests at the expense of polluting and destroying the environment, thereby exacerbating environmental problems.

\section{THE SOlutions TO THE MORAL NiHILISM IN CURRENT CHINA}

To solve this problem fundamentally, it is essential to combine the strategy of ruling of law and the ruling of morality. Specifically, the following points should be made:

\section{A. Comprehensively Promoting the Rule of Law}

Concerning the rule of law, it is necessary to make the rule of law become a strong support for the rule of morality, and make the rule of law provide the guarantee and support of the legal authority for the rule of morality. Specifically, some moral principles should be raised to the height of the law, so that the members of the society who do not abide by the moral norms are not only condemned and spurned, but also punished by the law. By doing this, some immoral members of society will pay a heavy price for their immoral behaviors, which will curb those behaviors.

\section{B. Strengthening the Construction of Social Morality}

In addition to comprehensively promoting the rule of law, we should also vigorously carry forward the socialist core values and use them to guide the moral construction of the whole society.(Yang Jinhua 14) At the same time, we should strengthen the preaching of the outstanding moral deeds from moral models in the country in order to drive the moral custom of the whole society. In addition to this, we should give full play to the role of education. In order to improve the moral consciousness and moral concepts of the members in the society, we should add the moral education in school education, family education, and vocational education and so on. In particular, we should start the moral education from the stage of kindergarten and primary school. In addition, we should pay attention to the encouragement for morally good behaviors, and perfect the incentive mechanism for morally good behaviors. Specifically, individuals and groups that make morally good behaviors should be given a high degree of spiritual and appropriate material rewards to encourage them. And this will encourage and guide more individuals and groups to do morally good behaviors, thus a good social moral atmosphere will form.

\section{CONCLUSION}

In conclusion, to solve the problem of the Moral Nihilism in current China, we must combine the rule of morality with the rule of law.

On the one hand, with the rule of law as the guarantee of rule of morality, those social members who do not abide by the moral norms will not only be condemned and spurned, but also be punished by law. By doing this, some immoral members of society will pay a heavy price for their immoral behaviors, which will curb those behaviors.

On the other hand, the rule of morality should be used as a complement to the rule of law. At present, the system of rule of law in Chinese society is still being formed and perfected, and the changes in social situation and situation are drastic and rapid. Therefore, in the process of social operation, it is unavoidable that some legal systems are relatively lagging behind. In other words, there may be loopholes or blanks in some laws. Under the circumstances, there may be a small number of people who will make some behaviors to break through the moral bottom line, harming others and public interests of the society in order to make their own interests. However, their bad behaviors cannot be judged as illegal for the time being. At this point, morality is needed as a complementary force. We should carry forward socialist core values, strengthen moral educations and preach advanced deeds of moral models.(Yang Jinhua 14 ) By doing 
so, we can create a good social moral atmosphere and lead a good social moral fashion, which provides a useful supplement for the rule of law and a flexible binding force to solve the Moral Nihilism in current China.

\section{REFERENCES}

[1] Yang Jinhua. "The Moral Nihilism and the Criticism about it in the Age of Materialization". Studies in Ethics 7(2014): 10-14.

[2] Li Junxue. "Losting and Re-construction of Virtue Ethics - the Question and Solution of Current Virtue Education". Future and Development 4(2014): 89-93.

[3] Liu Bingyuan. “Axiology of Moral Nihilism”. Journal of University of Jinan (Social Science Edition) 6(2009): 40-44, 90.

[4] Sang Zhijian. "Moral Nihilism and the Space that Moral Education can Work". Education Research Monthly 12(2011): 70-72. 